\title{
POPULATION INTERRELATIONSHIPS
}

\section{FREQUENCY-DEPENDENT FITNESS IN LINUM}

\author{
M. A. KHAN*, P. D. PUTWAIN and A. D. BRADSHAW \\ Department of Botany, University of Liverpool
}

Received 2.v.74

\begin{abstract}
SUMmary
Models of interaction between two genotypes are described. The models, known as "replacement series" are based on spacing formulae which were first described by C. T. de Wit. It is assumed that the total number or density of individuals is held constant, but the proportion of the two components of the mixture is varied. The output of each component at the end of a period of growth is determined; this may be dry matter production, seed output or any other relevant parameter.

Four varieties, two linseed (Redwing and Valuta), two flax (Stormont Gossamer and Wiera), were grown at three densities in four varietal combinations, and were harvested after four and one-half month's growth. When total dry weight and seed number were plotted as replacement series graphs, the total yields of the mixtures were frequently greater than would be expected from the growth of pure stands. Thus there was some form of augmentative interaction between varieties which would lead to a stable equilibrium if the mixture was resown in successive years. In most of the varietal mixtures there was strong evidence that relative fitness values were frequency-dependent. Usually the relative fitness of one component decreased as its frequency in the mixture increased. The results showed that frequency-dependent selection occurred between genotypes of flax or linseed due to annidation. It appeared that the patterns of growth and maturity of flax and linseed were different. Flax grew more rapidly and matured earlier than linseed and this difference in timing of growth led to annidation.
\end{abstract}

\section{INTRODUGTION}

WHEN a single genotype of a plant species is grown at varying densities, the form of yield curve measured as seed output, dry matter production, etc., is that shown in fig. 1. At low densities the individuals are sufficiently far apart that they do not affect one another. The yield per individual is constant and the yield per unit area is directly related to the density. We can refer to this relationship as type A.

At higher densities, however, individuals begin to affect each other in that there is an insufficiency of particular environmental supplies. As a result, because of individual phenotypic plasticity, in the sense of Bradshaw (1965), the yield per individual begins to diminish, and the simple relationship of yield per unit area to density begins not to hold. After a certain point environmental limitations are usually such that the yield per individual becomes directly and inversely related to density and yield per unit area becomes stable and independent of density. The range of densities over

* Present address: Department of Plant Breeding and Genetics, Agricultural University, Lyallpur, Pakistan. 
which this can occur depends on the degree to which the yield per individual can vary, i.e. on the plasticity of the species concerned. We can refer to this relationship as type $B$. The whole relationship has been expressed as $1 / w=A d+B$, where $w$ is the individual plant weight, $d$ is density and $A+B$ are constants (Shinozaki and Kira, 1956).

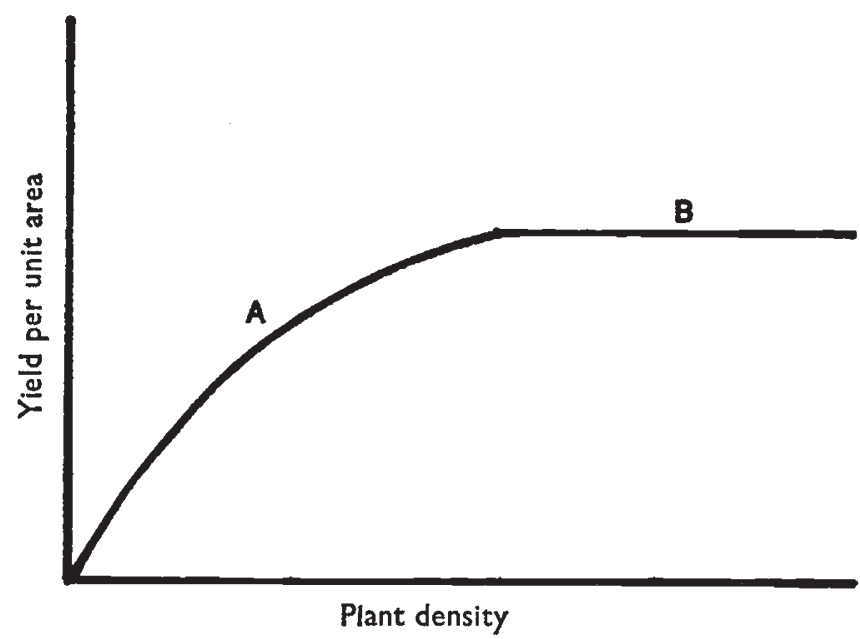

Fig. 1.-The typical relationship between yield per unit area and plant density.

\section{Models of INTERACTION BETWEEN TWO GENOTYPES}

When two different genotypes are put together in a mixture there are a number of possible outcomes which arise because of the interactions between and within each genotype. We can use the model first explored by de Wit (1960) in which it is assumed that the total number or density of individuals is held constant, but that the proportion of the two components of the mixture is varied. The contribution of each component at the end of the period of growth and interaction is determined; this may be in terms of seed output, dry matter production, tiller number or any other relevant parameter. The results are usually plotted as replacement series graphs.

There are many possible patterns of interaction and each of these can be computed using de Wit's model. The various outcomes are expressed as the relative output of each component of a mixture and are depicted in fig. $2 a$.

The relative yield of two genotypes will depend on whether they compete for the same environmental factors (they crowd for the same space-in the sense of de Wit) or whether they crowd for space which is not completely the same. The yields can be calculated from the following equations if the two genotypes crowd for the same space:

$$
\begin{aligned}
& O_{1}=K_{12} z_{1}\left(\left(K_{12}-1\right) z_{1}+1\right)^{-1} M_{1} \\
& O_{2}=K_{21} z_{2}\left(\left(K_{21}-1\right) z_{2}+1\right)^{-1} M_{2},
\end{aligned}
$$



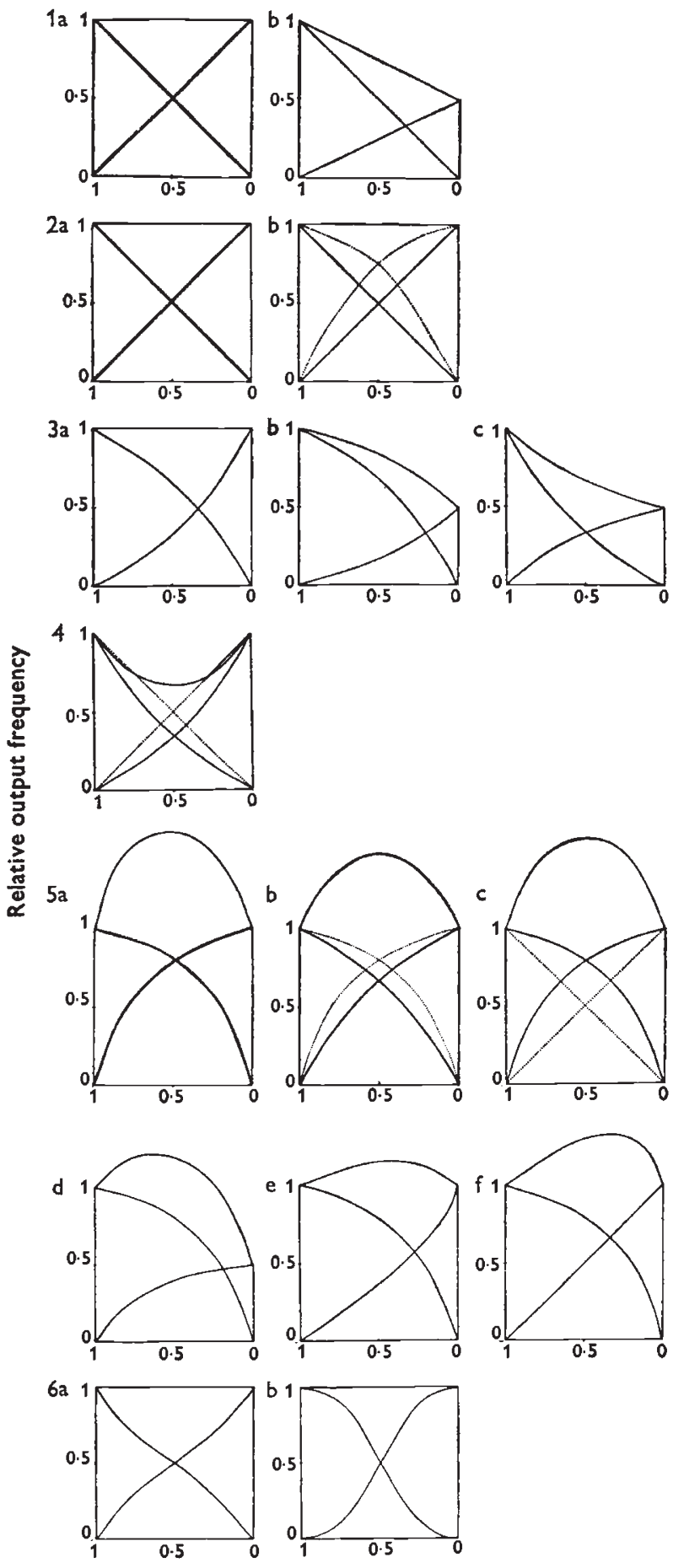

Relative input frequency

Fic. 2a.-Patterns of interaction between components in mixtures expressed as replacement series. 
where $\mathrm{O}_{1}$ and $\mathrm{O}_{2}$ are the yields of the two genotypes in the mixture; $z_{1}$ and $z_{2}$ are the relative input frequencies (usually seed frequencies) of the two components; $M_{1}$ and $M_{2}$ are the yields per unit area of each genotype. If the two genotypes crowd for space which is only partly the same, then the yields satisfy the following equations:

$$
\begin{aligned}
& O_{1}=K_{1(2 e)} z_{1}\left(\left(K_{1(2 e)}-1\right) z_{1}+1\right)^{-1} M_{1} \\
& O_{2}=K_{2(1 e)} z_{2}\left(\left(K_{2(1 e)}-1\right) z_{2}+1\right)^{-1} M_{2},
\end{aligned}
$$

where $K_{1(2 e)}$ and $K_{2(1 e)}$ represent relative crowding coefficients where one genotype crowds for space with the other genotype and also crowds for "empty space". This can be envisaged as space which has not been planted with either component.

The outcome of each type of interaction was determined by giving a suitable value to each of the relative crowding coefficients, and then the yields of the two components were computed over a range of relative input frequencies from 0 to 1 , at intervals of $0 \cdot 1$.

For ecological purposes a very important deduction we need to be able to make is whether such mixtures are stable, so that permanent cohabitation of the two components would occur, or whether one component will eliminate the other. This can best be done if the log of the ratio of the frequency of the two components when sown is plotted against the log of the ratio of the frequency of the two components when harvested, to give a ratio diagram. The slope and position of the line relative to a line of unit slope passing through the origin shows the stability of the mixture (de Wit, 1960). The ratio diagram for each pattern of interaction is plotted in fig. $2 b$.

\section{MODELS FOR EACH PATTERN OF INTERACTION}

1. There is no interaction whatever $\left(K_{12}=K_{21}=1 \cdot 0\right)$ because the density of each is so low that neither component impinges on the other, nor do members of one component impinge on each other. The result of variation in proportion is, therefore, very simple, being compounded of two relationships of the type A. However, the two components may (1a), or may not $(1 b)$, be equal in output.

The ratio diagrams show that the lines are of unit slope but only in $1 a$ does it pass through the origin indicating that the mixture is neutral (i.e. static but not self-stabilising). In $1 b$ the mixture will change toward the higher yielding component.

2. The interaction $\left(K_{12}=K_{21}=1 \cdot 0\right)$ between the components exists, but the two components are so alike that each reacts as if to its own kind. The result is a relationship superficially identical to 1 but for entirely different reasons: the individuals are at some particular density where a type $B$ relationship occurs. The ratio diagram shows that the mixture is neutral. This type of relationship can be distinguished from 1 , if each component of the mixture is also grown in pure stands at the same densities as in the mixture. The dotted lines in the replacement series graphs represent the yield of each component when growing alone. When an interaction between the components exists, then individuals growing alone will outyield individuals growing at the same density in a mixture $(2 b)$. 

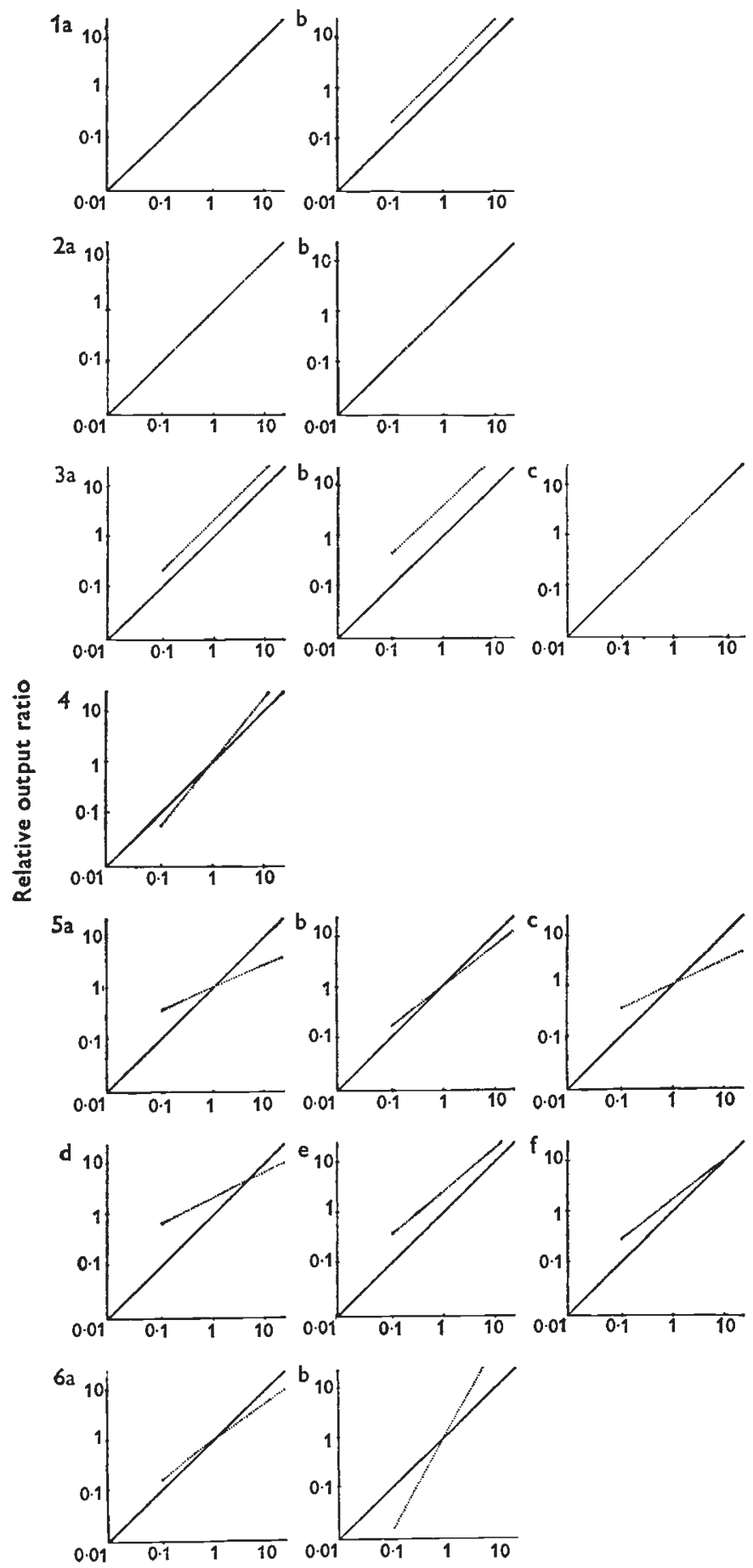

Relative input ratio

Fig. 2b.-Ratio diagrams of patterns of interaction shown in fig. $2 a$. 
3. Interaction exists $\left(K_{12}<1\right.$ or $\left.K_{21}<1\right)$ so that one component succeeds at the expense of the other. However, both components remain limited by the same environmental factors (they crowd for the same space-in the sense of de Wit), and, if the yields of the two pure stands are the same, the combined yield lies on the straight line between them. This is the normal form of competition ( $3 a$ ). It is termed complementary interaction by Schutz, Brim and Usanis (1968). The ratio diagram shows that this mixture is unstable: the successful component will progressively eliminate the other. The successful component can be that which does best in pure stand $(3 b)$ when the combined yield lies on a convex-shaped line. But the successful component is not necessarily the highest yielding in pure stand; it may be the one that does worst (3c). This is known as the Montgomery effect (Montgomery, 1912) and the combined yield lies on a concave-shaped line.

4. Negative interaction $\left(K_{12}>1\right.$ and $\left.K_{21}>1\right)$ exists such that the yield of both components and, therefore, that of the total is depressed. This is termed under-compensatory interaction by Schutz, Brim and Usanis (1968). This must be due to some sort of deleterious interaction. The ratio diagram shows that the mixture is unstable: whichever component has a higher initial frequency will succeed.

5. Some form of interrelationship between the two components exists $\left(K_{1(2 e)}>1\right.$ and $\left.K_{2(1 e)}>1\right)$ such that either both do better in mixture than would be normally expected from their density in the mixture, or one does better without the other suffering equivalently $\left(K_{1}(2 e)=1\right.$ and $\left.K_{2}(1 e)>1\right)$. In either case the combined yield is more than that expected from the performance of the pure stands: this we can call augmentative interaction. It is termed over-compensatory interaction by Schutz, Brim and Usanis (1968).

Augmentative interaction can have two causes. First, one or both components provide the other with some positive stimulation so that the latter grows better than it would have done in the absence of the former. This has been termed facilitation (Allee, 1951). Secondly, neither component provides the other with any positive stimulation but grows independently of it in such a way that it reacts more to its own density than to that of the other component.

If two components behave entirely independently of each other, then the yield curve of the mixture will be the sum of the yield curves of the two components growing separately and will be a humped shape $(5 a)$. Usually the components will not be entirely independent and some competitive interaction occurs. In this case the yield curve will be humped but will not equal the sum of the two components growing separately $(5 b)$. If any such independence occurs, the relationship cannot be called facilitation since there is no positive influence of one component on the other. It can more properly be termed annidation (Ludwig, 1950). It will occur where there is niche divergence.

These two forms of augmentative interaction yield results which cannot be distinguished from each other unless each component of the mixture is grown in the equivalent pure stand (i.e. at the density each component is when considered alone in the mixture). This is represented by the dotted lines in the replacement series graphs. If the total yield is more than the combined yield of the two components when grown in equivalent pure 
stand $(5 c)$, then facilitation must be involved, otherwise it may only be annidation $(5 a)$. Thus the results of Lewontin (1955) cannot be said to demonstrate facilitation, if the performance of the strains of Drosophila melanogaster in competition with white (50:50 mixture) is compared with their performance in pure culture at the density they were in competition, i.e. half the total density. There were only one or two exceptional mixtures where facilitation has certainly occurred. The results of Sokal and Huber (1964) are similar.

There are various ways in which augmentative interaction can occur. The first $(5 a, b, c)$, which is probably the commonest, is important because it has a property of considerable biological significance. Here the relative fitness of the components of the mixture will usually vary in relation to their frequency in the mixture, such that the component of low frequency has the higher fitness. This leads to a stable equilibrium which is demonstrated by the ratio diagram. It can occur even if the contribution of the two components is unequal $(5 d)$. However, this stability is not a necessary outcome of augmentative interaction. If one component does slightly worse than expected while the other does a lot better, the total yield will still be more than expected from pure stand performance but the mixture will not be stable $(5 e)$. If the yield of one component is exactly as expected the mixture will stabilise $(5 f)$.

6. Finally, situations can arise in which the relative crowding coefficient is frequency-dependent but where there is no augmentative interaction. Each component may yield more $(6 a)$ or less $(6 b)$ at low frequency, but the total output is no more than expected from the output of the pure stands and it lies on the straight line between them. This model is not considered by Schutz et al. (1968), but Putwain and Harper (1972) have shown that frequency-dependent interaction exists between male and female clones of Rumex acetosella which leads to a stable mixture.

Frequency-dependent patterns of interaction are important in determining the changes which can occur in the composition of mixtures. Their ecological significance has been discussed by Harper (1964). But the various types of augmentative interaction have not been distinguished. Since startling cases of augmentative interactions, sometimes specified as facilitation in error, are now forthcoming and which could be an indication of powerful forces causing the retention of variability in populations, it is important that they are distinguished.

In the course of an examination of the characteristics of flax and linseed varieties (Linum usitatissimum) they were combined in simple mixtures in varying frequencies and at varying densities. Flax has been selected for fibre production and is tall and early maturing whilst linseed has been selected for oilseed and is short and late maturing. Marked augmentative interactions occurred, leading to evidence of powerful frequency-dependent selection. The work on Drosophila populations described in the previous paper in this series (Seaton and Antonovics, 1967) and the recent work by Allard and Adams (1969) on interactions between genotypes extracted from barley populations, suggested that the interactions evolved by a process of co-evolution. The interaction between Linum genotypes could not have evolved by any process of co-evolution. But since the results show frequencydependent fitness in plants, of the sort leading to equilibrium situations, they are reported here. 


\section{Materials and methods}

Four varieties, two linseed (Redwing and Valuta), two flax (Stormont Gossamer and Wiera), were grown in four combinations.

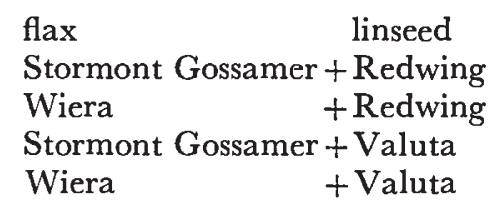

at five frequencies: $0: 100,25: 75,50: 50,75: 25,100: 0$, at three densities corresponding to the normal seed rates for linseed (the lowest density) and for flax (the highest density).

$\begin{array}{ccc}\text { Density } & \text { Distance between plants } & \text { Approximate seed wt/acre } \\ \mathrm{D}_{1} & 1 \cdot 41^{\prime \prime} & 40 \mathrm{lb} \\ \mathrm{D}_{2} & 1 \cdot 00^{\prime \prime} & 80 \mathrm{lb} \\ \mathrm{D}_{3} & 0 \cdot 81^{\prime \prime} & 120 \mathrm{lb}\end{array}$

The material was sown in the field in plots containing a total of 36 plants in a precise hexagonal arrangement surrounded by further seed broadcast at the appropriate density as guard material so that the size of all plots was $2 \mathrm{ft}$ by $2 \mathrm{ft}$. In the case of the 36 plants, two seeds were sown at each station and subsequently thinned to one. In the plots involving two varieties their positions were assigned at random. There were four replicates.

The experiment was sown in mid-May and harvested when mature in late September. At harvest the two components were separated and dried and the total dry weight, total seed number, individual seed weight and other associated characters determined.

\section{Results}

(i) Replacement series graphs

Actual values are plotted as replacement series graphs in figs. 3 and 4. An analysis of variance is not possible because the variance of populations of the two components are not independent. Therefore lowest significant differences $(\mathrm{P}<0.05)$ are given for dry weight and seed number per plot. It is clear that there is not a simple competitive relationship between varieties. There is nearly always increased growth of at least one variety which is not accompanied by any corresponding decrease in growth of the other variety: there may be increased growth of the other variety as well. So the total yields of the mixture very often are greater than would be expected from the growth of pure stands. This is more evident for seed number than for total dry weight. There is some form of augmentative interaction between varieties.

There are also clear varietal differences in performance in pure stands which are reflected in performance in mixture: there is no evidence of any lack of correspondence in performance. 
(ii) Ratio diagrams

If the results are plotted as ratio diagrams there are departures from the line of unit slope (fig. 5). In the majority of cases the slope of the lines are
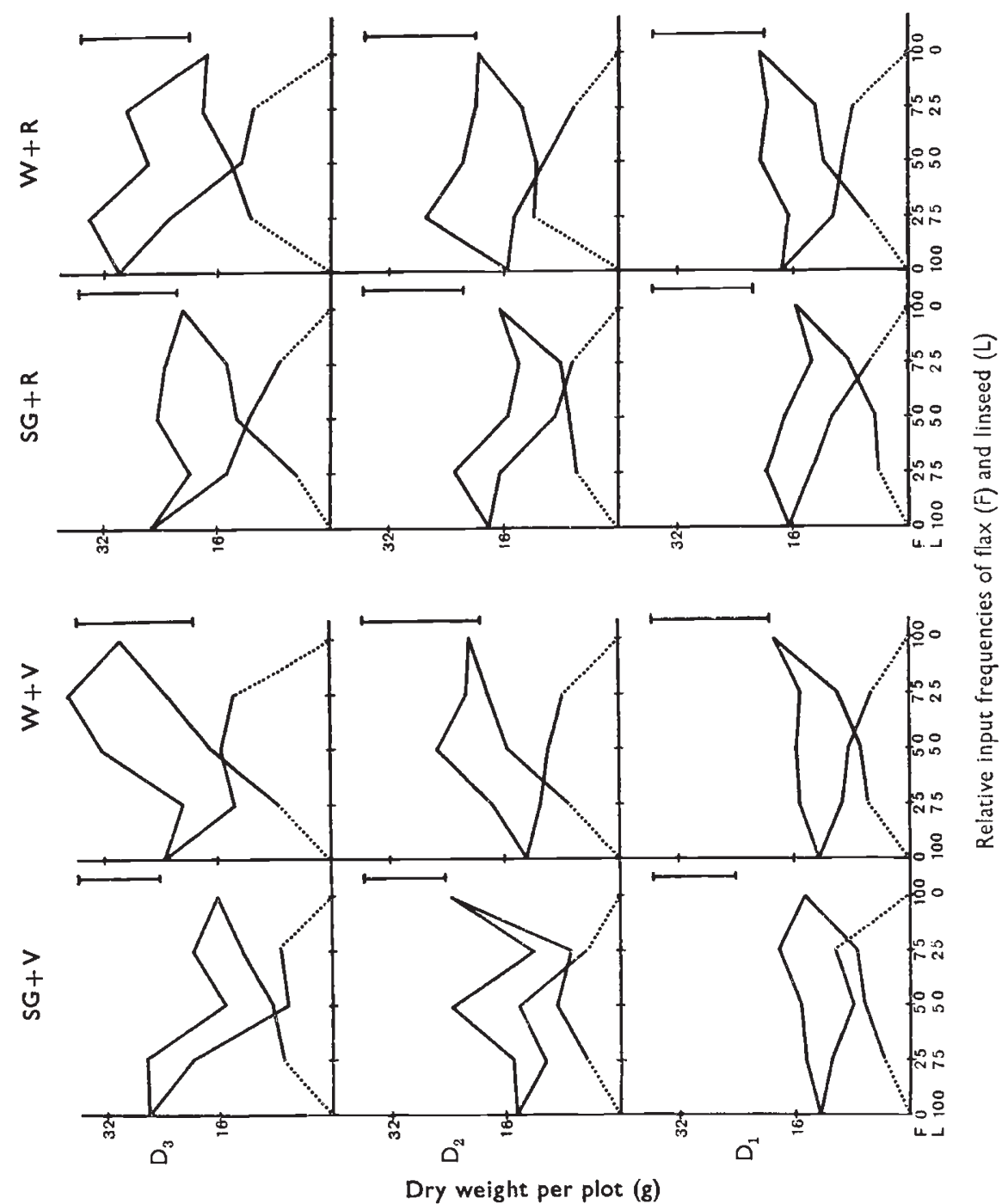

FIG. 3.-Replacement series graphs for dry weight per plot of flax and linseed varieties grown in mixtures at different densities.

significantly less than unity (table 1). Such a relationship is evidence of a frequency dependent interaction between varieties which must lead to a stable equilibrium if the mixture was to be sown in successive years. For at high input ratio of flax to linseed, output ratios are lower, while at low input ratios, output ratios are higher. If resown on successive occasions the mixture 
would tend to proceed to a composition where the input and output ratios are the same. This is where the lines intersect the line of unit slope.

Different varietal mixtures all show the same property, but the equilibrium frequencies are different in different combinations. The equilibrium
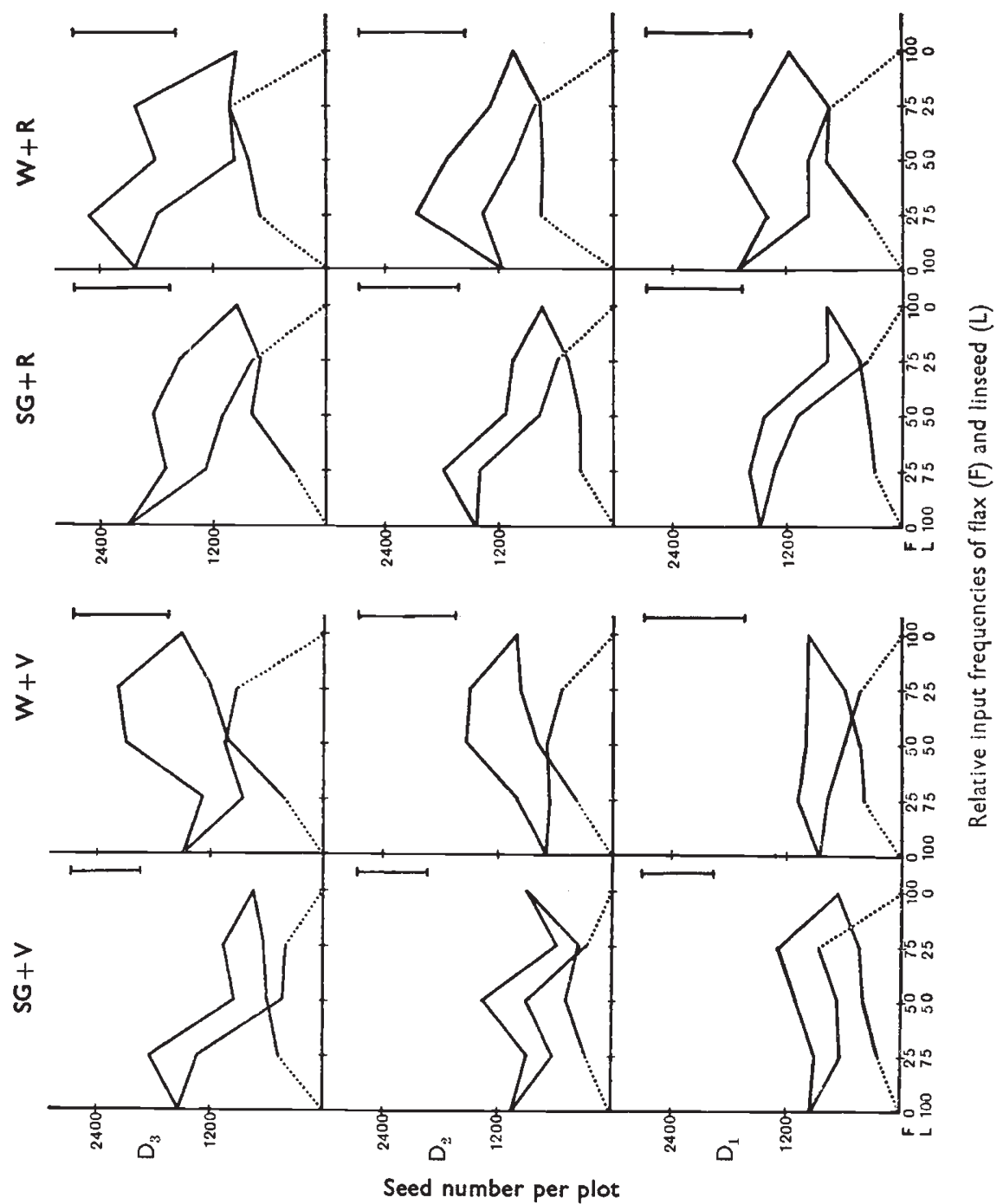

Fig. 4.-Replacement series graphs for seed number per plot of flax and linseed varieties grown in mixtures at different densities.

point tends to be shifted towards higher flax/linseed ratios at higher densities, although this does not occur in some varietal combinations. The pattern of relationship is the same for dry weight as for seed number, but the interaction effect is more marked for seed number. 


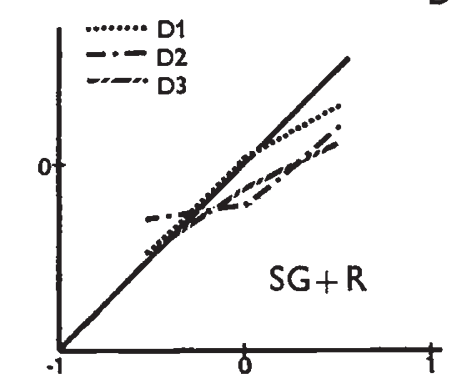

Dry weight
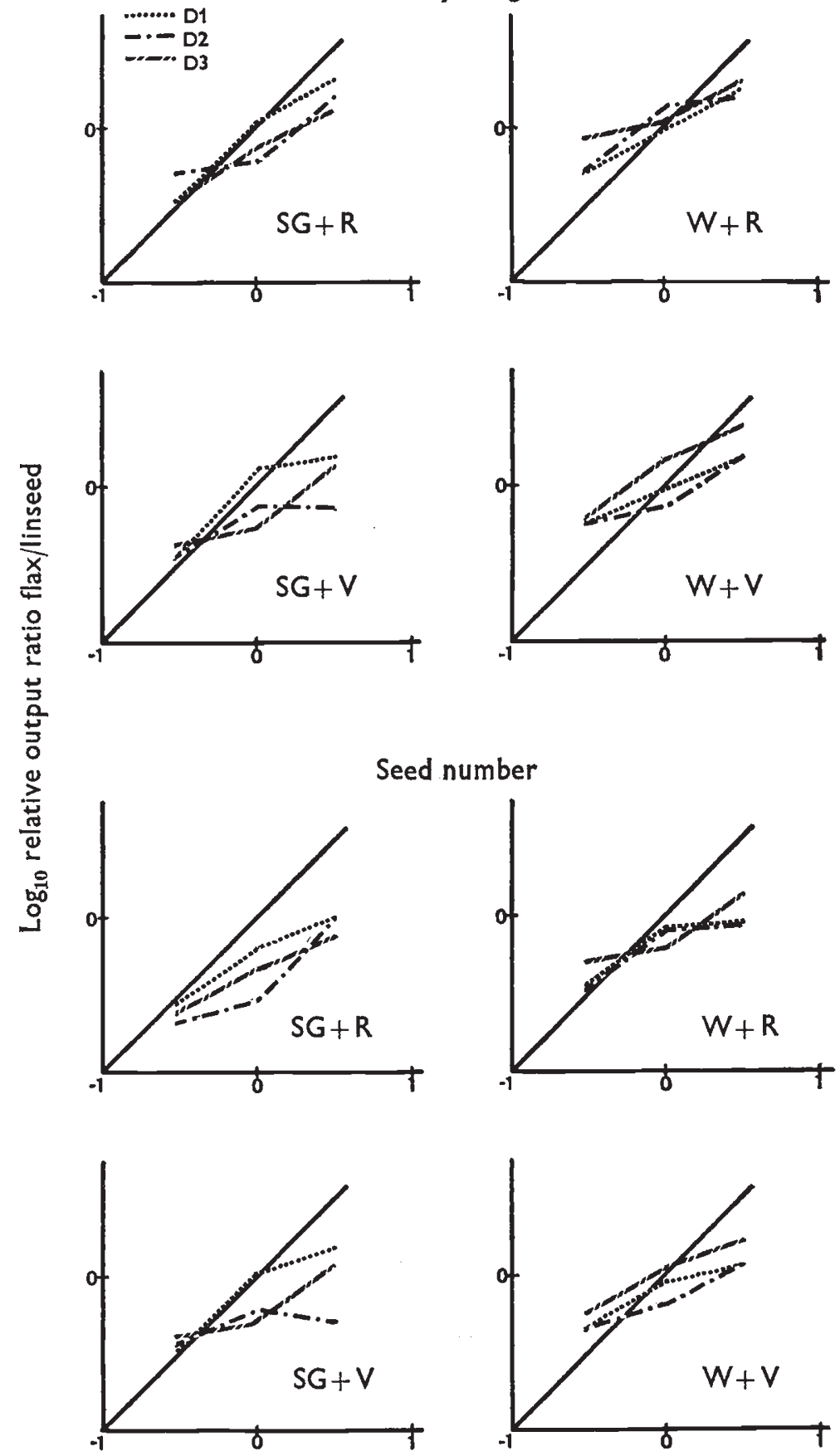

$\log _{10}$ relative input ratio flax/linseed

FIG. 5.-Ratio diagrams for dry weight and seed number of flax and linseed varieties grown in mixtures of different densities. 
TABLE 1

Ratio diagrams: regression analysis of the relationship between proportion of flax and linseed varieties sown at different densities and the proportion of their seed output or dry weight when harvested

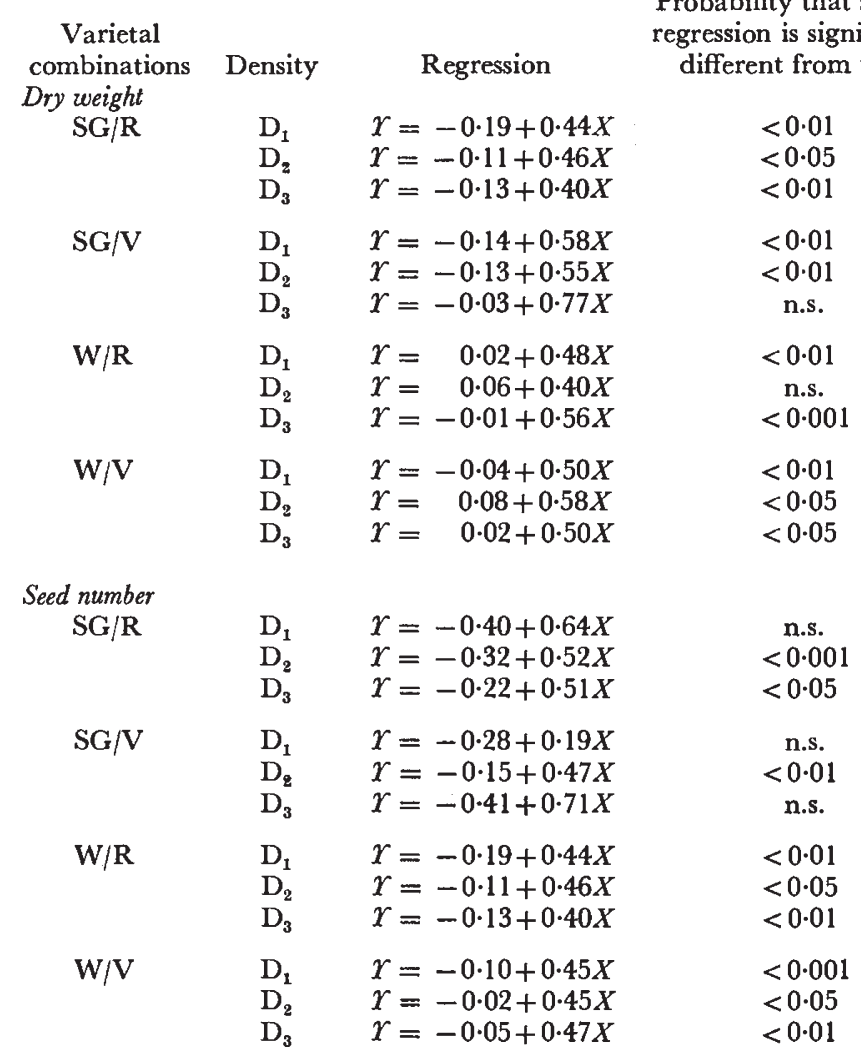

(iii) Relative fitness

The relative performance of the two components in the mixtures can be expressed in terms of relative fitness where the relative performances are compared on a single plant basis (de Wit, 1960).

$$
\alpha F L=\frac{O_{F}}{Z_{F}} / \frac{O_{L}}{Z_{F}},
$$

where $\alpha F L$ is the relative fitness of flax compared with linseed; $O_{F}$ and $O_{L}$ are the yields per plot of the flax or linseed components in the mixture; $Z_{F}$ and $Z_{L}$ are the corresponding numbers of seed of flax or linseed sown.

Here the important character is the relative abilities of the two components to contribute to the next generation. For this reason relative fitness values are given only for seed number (table 2 ).

The overwhelming result is the effect of frequency on fitness. If the results are pooled over varieties and densities, the relative fitness of flax at lower frequency in a mixture is 1.22 , at medium frequency 0.76 , and at 
TABLE 2

Relative fitness of flax and linseed varieties at different frequencies for seed number

\begin{tabular}{|c|c|c|c|c|c|}
\hline \multirow[t]{2}{*}{$\begin{array}{c}\text { Varietal } \\
\text { combinations }\end{array}$} & \multicolumn{2}{|c|}{ Proportions } & \multicolumn{3}{|c|}{ Densities } \\
\hline & Flax & Linseed & $D_{1}$ & $\mathrm{D}_{2}$ & $\mathrm{D}_{3}$ \\
\hline $\mathrm{SG} / \mathrm{R}$ & $\begin{array}{r}9 \\
18 \\
27\end{array}$ & $\begin{array}{r}27 \\
18 \\
9\end{array}$ & $\begin{array}{l}0.64 \\
0.32 \\
0.31\end{array}$ & $\begin{array}{l}0.81 \\
0.52 \\
0.28\end{array}$ & $\begin{array}{l}0.88 \\
0.71 \\
0.31\end{array}$ \\
\hline $\mathbf{W} / \mathbf{R}$ & $\begin{array}{r}9 \\
18 \\
27\end{array}$ & $\begin{array}{r}27 \\
18 \\
9\end{array}$ & $\begin{array}{l}1.03 \\
0.77 \\
0.32\end{array}$ & $\begin{array}{l}1.71 \\
0.70 \\
0.52\end{array}$ & $\begin{array}{l}1.18 \\
0.85 \\
0.34\end{array}$ \\
\hline $\mathrm{SG} / \mathrm{V}$ & $\begin{array}{r}9 \\
18 \\
27\end{array}$ & $\begin{array}{r}27 \\
18 \\
9\end{array}$ & $\begin{array}{l}1.15 \\
0.67 \\
0.17\end{array}$ & $\begin{array}{l}1.39 \\
0.59 \\
0.46\end{array}$ & $\begin{array}{l}1 \cdot 11 \\
1 \cdot 14 \\
0.52\end{array}$ \\
\hline $\mathrm{W} / \mathrm{V}$ & $\begin{array}{r}9 \\
18 \\
27\end{array}$ & $\begin{array}{r}27 \\
18 \\
9\end{array}$ & $\begin{array}{l}1.50 \\
0.72 \\
0.44\end{array}$ & $\begin{array}{l}1 \cdot 71 \\
1 \cdot 16 \\
0.53\end{array}$ & $\begin{array}{l}1.51 \\
0.96 \\
0.44\end{array}$ \\
\hline
\end{tabular}

higher frequency $0 \cdot 39$. There is a more than three-fold change in fitness with change in frequency.

\section{(iv) Relative crowding coefficients}

The final step in the analysis is to relate the performance in mixtures to the performance in pure stands. This can be done by calculating the relative crowding coefficients (de Wit, 1960) obtained by adjusting the relative fitness values by the yield in pure stands

$$
K_{F L}=\frac{O_{F}}{Z_{F}} / \frac{O_{L}}{Z_{L}} / \frac{M_{F}}{M_{L}},
$$

where $K_{F L}$ is the relative crowding coefficient and $M_{F}, M_{L}$ are the corresponding yields per plot of flax or linseed in pure stand. By this adjustment we have a precise measure of the influence which one variety has on the other, uncomplicated by reactions unconnected with interaction effects. If $K_{F L}=1$, they are equal in their interaction; if $K_{F L}>1$, then flax is succeeding relative to linseed, and if $K_{F L}<1$, the reverse. $K_{F L}$ is a direct measure of relative fitness adjusted for differences in pure stand performance.

We can also calculate individual crowding coefficients

$$
K_{F}=\frac{O_{F}}{Z_{F}} / \frac{M_{F}}{Z_{M F}}, \quad K_{L}=\frac{O_{L}}{Z_{L}} / \frac{M_{F}}{Z_{M L}},
$$

where $K_{F}$ and $K_{L}$ are individual crowding coefficients and $Z_{M F}$ and $Z_{M L}$ are the numbers of seeds of flax or linseed sown in pure stand. These compare the single plant performance of flax or linseed in a mixture with its equivalent performance in pure stand. There is a simple relationship between $K_{F L}$ and $K_{F}$ and $K_{L}$

$$
K_{F L}=\frac{K_{F}}{K_{L}}
$$


The values (table 3 ) show that the relative crowding coefficients are by no means constant. They change violently and regularly with the frequency of the two components in the mixture, as do the relative fitness values.

The individual crowding coefficients show that both flax and linseed are often doing better in a mixture than in pure stand. As would be expected from the values for $K_{F L}$, this occurs mainly when they are at low frequency. If we compare the two values, for flax and linseed, for any one variety combination at any one density, when both are at low frequency, we do not find any clear evidence that either is able to take advantage of

TABLE 3

Relative and individual crowding coefficients for flax and linseed varieties at different frequencies

\begin{tabular}{|c|c|c|c|c|c|c|c|c|c|c|c|}
\hline \multirow{3}{*}{$\begin{array}{c}\text { Varietal } \\
\text { combinations }\end{array}$} & & & \multicolumn{9}{|c|}{ Densities } \\
\hline & \multicolumn{2}{|c|}{ Proportions } & \multicolumn{3}{|c|}{$\underbrace{D_{1}}$} & \multicolumn{3}{|c|}{$\underbrace{D_{2}}$} & \multicolumn{3}{|c|}{$\underbrace{D_{9}}_{9}$} \\
\hline & Flax & Linseed & $\kappa_{F L}$ & $\kappa_{F}$ & $\kappa_{L}$ & $K_{F L}$ & $\kappa_{F}$ & $\kappa_{L}$ & $\kappa_{F L}$ & $\kappa_{F}$ & $\kappa_{L}$ \\
\hline SG/R & $\begin{array}{r}9 \\
18 \\
27\end{array}$ & $\begin{array}{r}27 \\
18 \\
9\end{array}$ & $\begin{array}{l}1.27 \\
0.64 \\
0.61\end{array}$ & $\begin{array}{l}1.51 \\
0.92 \\
0.65\end{array}$ & $\begin{array}{l}1.18 \\
1.44 \\
1.07\end{array}$ & $\begin{array}{l}1.53 \\
0.98 \\
0.53\end{array}$ & $\begin{array}{l}1.96 \\
1.02 \\
0.83\end{array}$ & $\begin{array}{l}1.29 \\
1.04 \\
1.57\end{array}$ & $\begin{array}{l}1.91 \\
1.55 \\
0.68\end{array}$ & $\begin{array}{l}1.60 \\
1.67 \\
1.04\end{array}$ & $\begin{array}{l}0.84 \\
1.07 \\
1.55\end{array}$ \\
\hline$W / R$ & $\begin{array}{r}9 \\
18 \\
27\end{array}$ & $\begin{array}{r}27 \\
18 \\
9\end{array}$ & $\begin{array}{l}1.59 \\
1.19 \\
0.49\end{array}$ & $\begin{array}{l}1.19 \\
1.33 \\
0.85\end{array}$ & $\begin{array}{l}0.75 \\
1.12 \\
1.75\end{array}$ & $\begin{array}{l}1.84 \\
0.75 \\
0.56\end{array}$ & $\begin{array}{l}2 \cdot 80 \\
1.37 \\
0.98\end{array}$ & $\begin{array}{l}1.52 \\
1.82 \\
1.75\end{array}$ & $\begin{array}{l}2.56 \\
1.84 \\
0.73\end{array}$ & $\begin{array}{l}3.00 \\
1.76 \\
1.43\end{array}$ & $\begin{array}{l}1.17 \\
0.95 \\
1.96\end{array}$ \\
\hline $\mathrm{SG} / \mathrm{V}$ & $\begin{array}{r}9 \\
18 \\
27\end{array}$ & $\begin{array}{r}27 \\
18 \\
9\end{array}$ & $\begin{array}{l}1 \cdot 62 \\
0 \cdot 95 \\
0 \cdot 24\end{array}$ & $\begin{array}{l}1.49 \\
1.37 \\
0.91\end{array}$ & $\begin{array}{l}0.92 \\
1.44 \\
3.74\end{array}$ & $\begin{array}{l}1.56 \\
0.66 \\
0.52\end{array}$ & $\begin{array}{l}1.26 \\
1 \cdot 10 \\
0.53\end{array}$ & $\begin{array}{l}0.80 \\
1.68 \\
1.01\end{array}$ & $\begin{array}{l}2.23 \\
2.29 \\
1.05\end{array}$ & $\begin{array}{l}2 \cdot 62 \\
1.35 \\
1 \cdot 14\end{array}$ & $\begin{array}{l}1.17 \\
0.59 \\
1.08\end{array}$ \\
\hline$w / V$ & $\begin{array}{r}9 \\
18 \\
27\end{array}$ & $\begin{array}{r}27 \\
18 \\
9\end{array}$ & $\begin{array}{l}1.27 \\
0.61 \\
0.37\end{array}$ & $\begin{array}{l}1.54 \\
0.89 \\
0.77\end{array}$ & $\begin{array}{l}1.22 \\
1.47 \\
2.09\end{array}$ & $\begin{array}{l}1.25 \\
0.85 \\
0.39\end{array}$ & $\begin{array}{l}1.54 \\
1.69 \\
1.28\end{array}$ & $\begin{array}{l}1.24 \\
1.99 \\
3.26\end{array}$ & $\begin{array}{l}1.47 \\
0.93 \\
0.43\end{array}$ & $\begin{array}{l}1.17 \\
1.33 \\
1.07\end{array}$ & $\begin{array}{l}0.79 \\
1.43 \\
2.52\end{array}$ \\
\hline
\end{tabular}

low frequency more than the other; flax is better than linseed in six cases out of 12. The same is true when they are both at high frequency, flax is better than linseed in five cases out of 12 .

But there is evidence from the relative crowding coefficients that the balance between flax and linseed differs in the different varietal combinations used, and that there is an effect of density. The relative crowding coefficient of flax increases with density. These effects are more pronounced for total seed number than for total dry weight, but the pattern for dry weight is the same.

\section{(v) Comparison with behaviour at equivalent density in pure stand}

Plots of pure stand at every density, equivalent to densities of individual components in each mixture were not sown. However, we can compare performance of flax and linseed in $50: 50$ mixture at $\mathrm{D}_{2}$ with performance in pure stand at $D_{1}$. The ratios of these values are given in table 4 .

Except in a single case, the yield in mixture is always less than in equivalent pure stand. There is therefore no direct evidence for facilitation. It would anyway be difficult to envisage how facilitation could occur. 
TABLE 4

Performance of flax and linseed varieties in 50:50 mixture as a fraction of performance in pure stand at equivalent density

\begin{tabular}{lcccc} 
& \multicolumn{4}{c}{ Varietal combinations } \\
\cline { 2 - 6 } $\begin{array}{l}\text { Seed number } \\
\text { Linseed }\end{array}$ & 0.99 & 0.86 & 0.52 & 0.63 \\
Flax & 0.78 & 0.88 & 0.50 & 0.63 \\
& & & & \\
Dry weight & & & & \\
$\quad$ Linseed & 1.18 & 0.83 & 0.53 & 0.60 \\
Flax & 0.64 & 0.83 & 0.47 & 0.57
\end{tabular}

\section{(vi) Other characteristics}

Other characters were measured in the course of the experiment but on the whole do not contribute anything further. The values for individual seed weight are however of interest. Usually the individual seed weight of both flax and linseed is remarkably constant (Khan, 1963). But in these experiments there was a distinct change. In mixtures the individual seed weight of linseed was higher than in pure stand, particularly where the flax : linseed ratio was $75: 25$. This was not so for flax (fig. 6).

The explanation of this appears to lie in the patterns of growth and maturity of the two types. Flax was slightly more rapid growing and matured distinctly earlier than linseed (approximately 3 weeks). At maturity the leaves shrivelled and all that was left were the stems and capsules. Thus at the time of seed development in linseed a considerable amount of space suddenly becomes available to the plants at a time when the development of new flowers is lessening. So the products of any increased growth go mainly into the seed. Since the greatest release of space for linseed occurs in those mixtures where it is at a low frequency, it is here that the effect would be greatest.

\section{Discussion}

(i) The nature of the interaction

The fact that the components of the mixture both do better than expected, and that therefore the total yield curve is humped, indicates that the increased performance of one component is not accompanied by decreased performance of the other. The interaction is augmentative and appears to be due to annidation. If it is annidation it is not complete, since yield in mixture is reduced compared with yield in equivalent pure stand: but complete annidation is hardly to be expected. It seems unlikely that some chemical or other positive stimulation between components is occurring. It is more reasonable to look for something which is related to general differences between flax and linseed. The most obvious difference is that of timing of growth, which would lead to annidation, since flax can first have the predominant share of the environment and then linseed. Further investigation indicates that this is so (Harper, 1970).

It is interesting that the interaction is affected by density. We know 
that the growth form of flax is different to that of linseed and that linseed has a greater ability to respond to wide spacing than flax which can be related to the fact that it is normally grown at lower densities than flax
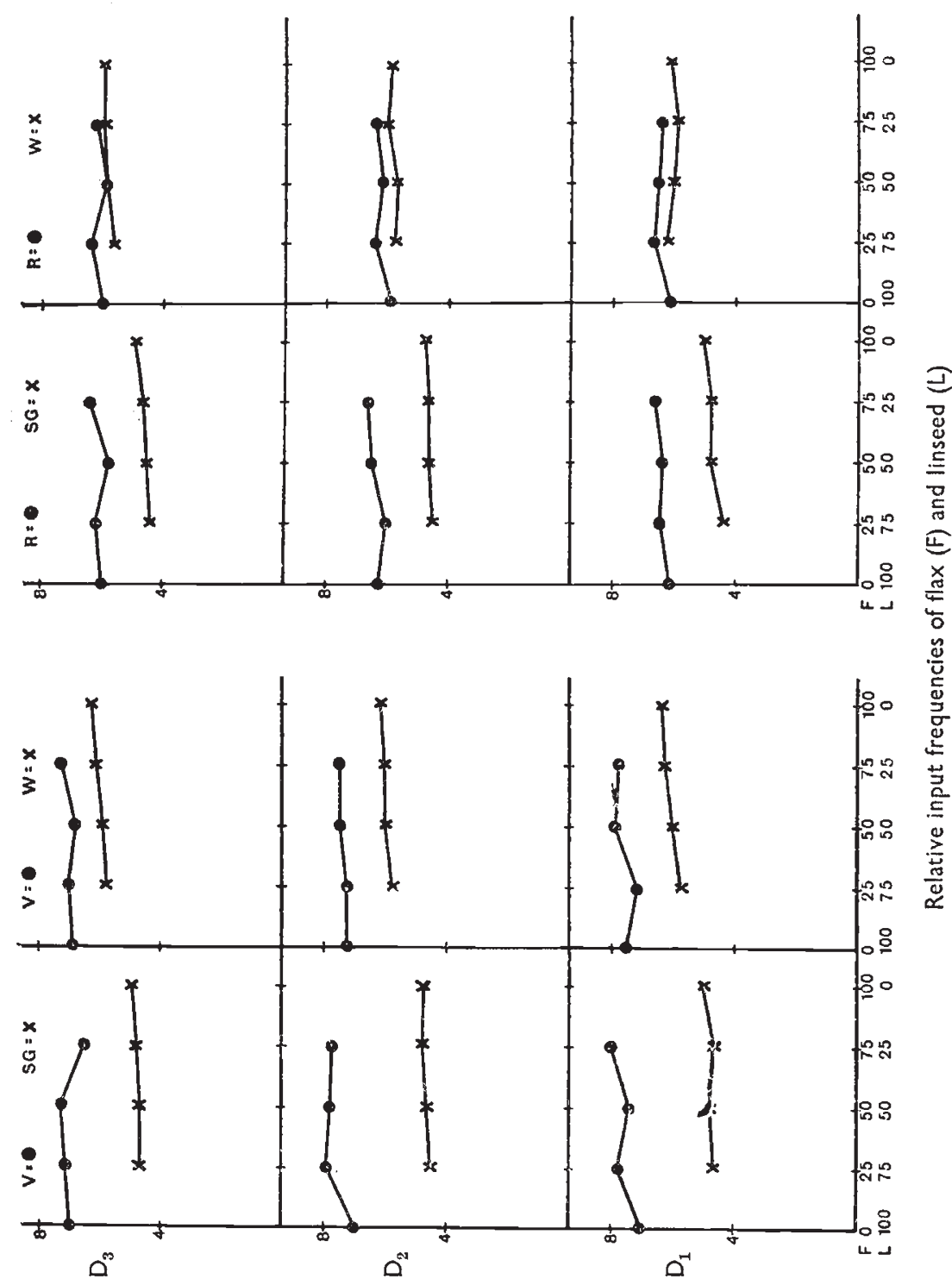

Frg. 6.-Individual seed weight of flax and linseed varieties in mixtures (mg).

(Bradshaw, 1965). But in the mixtures if we allow for any differences that are to be found in pure stand, we find from the relative crowding coefficient that the interaction is still density-dependent: the effect on flax of competition from linseed is less at high density. So we have a characteristic of flax related to density separate from what is apparent in pure stands. 


\section{(ii) Frequency dependent selection}

The results show that powerful frequency-dependent selection can occur between genotypes of a plant species in mixed populations, due to positive, augmentative interactions, almost certainly because of annidation. This is important because this interaction has been considered as occurring mainly between species. However, evidence of it occurring between genotypes is now accumulating. In the experiments of Seaton and Antonovics (1967) they were able to show that such a relationship could evolve and that it would lead to an equilibrium condition. In plants there is now evidence of powerful frequency dependent interactions between the sexes of Rumex acetosella (Putwain and Harper, 1972), which leads to an equilibrium between the sexes being maintained in the vegetative phase. This equilibrium probably depended on non-synchronous light interception by the two sexes during the growing season. Rhodes (1969) provides evidence that the augmentative interaction between two varieties of perennial ryegrass (S23 and Ba 6280) was due, in the mixture, to a greater residual leaf area after defoliation and to a greater percentage of incident light being distributed over the most photosynthetically efficient tissue. These augmentative interactions which are probably due to annidation occurred only under frequent cutting and a high level of fertiliser. Allard and Adams (1969) show that very marked augmentative interaction occurs between genotypes from a barley composite cross. They presume it will give frequency-dependent selection for an equilibrium, but although this is reasonable, there is no direct evidence for it, since they have observations only on one frequency in mixture. The model of Schutz, Brim and Usanis (1968), which they explore, assumes the same since the component of fitness of a genotype due to interaction with other genotypes is made dependent on the frequency of the latter.

Many cases of frequency-dependent selection are appearing, e.g. Drosophila melanogaster esterase-6 isoalleles (Kojima and Yarborough, 1967) and at the alcohol dehydrogenase locus (Kojima and Tobari, 1969a). Kojima and Tobari (1969b) also find in $D$. ananassae that frequency-dependent selection influenced chromosome inversion frequencies. We have little evidence whether these situations have arisen by annidation or by some direct interaction of a proper facilitation type. It cannot be due to the frequency-dependent mating found by Spiess (1968) and Erhman and Petit (1968). However, the experiments of Huang, Singh and Kojima (1971) indicate that the response of different genotypes to conditioning of the media is responsible for the frequency dependence of the esterase- 6 locus of $D$. melanogaster. The fitness of the more abundant genotype tends to be lowered because it more often uses a medium which has been conditioned by the same genotype. These interactions appear to have arisen by annidation although the frequency-dependent model (6) cannot be ruled out. Other similar cases of frequency-dependent relationships between genotypes unfortunately do not usually allow us to decide about their cause.

The overall density of a plant or animal population is also important in determining whether frequency-dependent selection occurs. The intensity of frequency-dependent selection in the esterase- 6 locus of $D$. melanogaster is dependent on the overall population density (Kojima and Huang, 1972). Frequency-dependent selection takes place mainly when the population 
density is high. This type of response to density parallels the densitydependent interaction which we have found in mixtures of flax and linseed.

Whatever their cause, all the various examples of frequency-dependent selection are important in that they demonstrate a powerful cause for the retention of variability in natural populations, as Schutz, Brim and Usanis (1968) and Allard and Adams (1969) in particular, have argued. The phenomenon is important, because in such populations where genotypes are at equilibrium frequencies selection will not occur so that there will be no substantial genetic load, although random genetic drift will create some segregational load (Kojima, 1971). But as a result, frequencydependent selection will be difficult to detect unless experiments are specifically designed with this in view. In many circumstances experiments based on the de Wit models can be of great value in determining whether frequency-dependent selection occurs.

\section{REFERENCES}

ALLARD, R. W., AND ADAMS, J. 1969. The role of inter-genotypic interactions in plant breeding. Proc. 12th int. Cong. Genetics, vol. 3, 349-370.

Allee, w. c. 1951. Co-operation among Animals. New York.

BRADSHAW, A. D. 1965. Evolutionary significance of phenotypic plasticity in plants. Adv. Genet., 13, 115-155.

EHRMAN, L., AND PETT, c. 1968. Genotype frequency and mating success in the willistoni species group of Drosophila. Evolution, 22, 649-658.

HARPER, J. L. 1964. The nature and consequence of interference amongst plants. Proc. 11th int. Cong. Genet. 1963, 465-482.

harper, J. L. 1970. The Role of Predation in Vegetation Diversity. Diversity and Stability in Ecological Systems. Brookhaven National Laboratory, New York, pp. 48-62.

HUANG, s. L., SINGH, M., AND KOJIMA, K. 1971. A study of frequency dependent selection observed in the esterase 6 locus of Drosophila melanogaster using a conditioned media method. Genetics, 68, 97-104.

KHAN, M. A. 1963. Physiologic and genetic analysis of varietal differences within Linum usitatissimum (flax and linseed). Ph.D. thesis, Univ. Wales.

KoJIMA, к. 1971. The distribution and comparison of "Genetic Loads" under heterotic selection and simple frequency-dependent selection in finite populations. Theoret. Pop. Biol., 2, 159-173.

KOJIMA, K., AND HUANG, s. L. 1972. Effects of population density on the frequency-dependent selection in the esterase-6 locus of Drosophila melanogaster. Evolution, 26, 313-321.

KOJIMA, K., AND TOBARI, Y. N. 1969a. The pattern of viability changes associated with genotype frequency at the alcohol dehydrogenase locus in a population of Drosophila melanogaster. Genetics, 61, 201-209.

KojIma, K., AND tobaRI, צ. N. 1969b. Selective modes associated with karyotypes in Drosophila ananassae. II. Heterosis and frequency-dependent selection. Genetics, 63, 639-651.

KOJIMA, K., AND Yarbrough, к. м. 1967. Frequency-dependent selection at the esterase 6 locus in Drosophila melanogaster. Proc. Nat. Acad. Sci. U.S.A., 57, 645-649.

LEWONTIN, R. C. 1955. The effects of population density and composition on viability in Drosophila melanogaster. Evolution, 9, 27-41.

Ludwig, w. 1950. Zur Theorie der Konkurrenz. Die Annidation (Einischung) als funfter Evolutionsfaktor. Neue Ergebnisse in Probleme der Zoologae, 516-537.

montgomery, E. G. 1912. Competition in cereals. Bull. Nebr. agr. exp. Sta., 24, 1-22.

PUTWAiN, P. D., AND HARPER, J. L. 1972. Studies in the dynamics of plant populations. V. Mechanisms governing the sex ratio in Rumex acetosa and $R$. acetosella. $\mathcal{F}$. Ecol., $60,113-129$.

RHODEs, 1. 1969. The yield, canopy structure and light interception of two rye grass varieties in mixed and monoculture. 7. Brit. Grass. Soc., 24, 123-127.

SCHUTZ, w. M., BRIM, C. A., AND USANIS, s. A. 1968. Intergenotypic competition in plant populations. I, Feedback systems with stable equilibria in populations of autogamous homozygous lines. Crop Sci., 8, 61-66. 
SEAton, A. P. C. AND ANtonovics, J. 1967. Population interrelationships. I. Evolution in mixtures of Drosophila mutants. Heredity, 22, 19-33.

SHINOZAKI, K. AND KIRA, T. 1956. Intraspecific competition among higher plants. VII. Logistic theory of the G-D effect. F. Inst. Polytech. Osaka Cy Univ., Ser. D., 7, 35-72.

SOKAL, R. R. AND HUBER, I. 1964. Competition among genotypes in Tribolium castaneum at varying densities and gene frequencies (the sooty locus). Am. Nat., 97, 169-184.

sPIEss, E. B. 1968. Low frequency advantage in mating of Drosophila pseudo-obscura karyotypes. Am. Nat., 102, 363-380.

wrT, c. T. DE 1960. On competition. Versl. landbouwk. Onderz. Rijkslandbproestfn., 66, 8-82. 